\title{
DIMENSÕES DA CRISE MUNDIAL DO CAPITALISMO. EUA, EUROPA, CHINA, AMÉRICA LATINA: Argentina, Brasil ${ }^{1}$
}

\author{
INTRODUÇÃO
}

Jorge Nóvoa *

Denominamos este dossiê de Dimensões $d a$ crise mundial do capitalismo. EUA, Europa, China, América Latina: Argentina, Brasil. Ele não pretende uma abordagem completa daquilo que a mídia denomina de crise na atualidade. O significado da palavra crise que - de tanto ser repetida, parece ter assumido a identidade de um ser metafísico, e, portanto, meta-histórico! A consulta aos dicionários nos informa que o substantivo feminino crise vem do latim crìsis, is como momento de mudança súbita, e do gr. krísis, eós como ação, faculdade de indecisão em momento difícil. Na medicina, a pa-

\footnotetext{
* Doutor em Sociologia. Professor do Departamento de Sociologia e da Pós-Graduação da UFBA. Professor Convidado da Université de Paris III - Sorbonne, em Pósdoutoramento na École des Hautes Études em Sciences Sociales.

Estrada de São Lázaro, 197. Cep: 40210-730 - Federação

- Salvador - Bahia - Brasil. jlbnovoa@yahoo.com.br

${ }^{1}$ A organização deste dossiê sobre a Crise é uma contribuição que se inspirou, também, numa modesta homenagem que queria realizar, há muito tempo, a duas grandes figuras das ciências sociais do Brasil. São elas Guaracy Adeodato - com quem iniciei na UFBA minhas pesquisas sociológicas de campo e de quem consegui muita ajuda - e a Anete Brito Leal Ivo de quem obtive incentivo e apoio, em muitos momentos. As duas, além de professoras, me coordenaram no Centro de Recursos Humanos (CRH) da UFBA, dos mais importantes centros de investigação em ciências sociais deste país.
}

lavra encontra o significado da evolução de uma doença (para melhor ou pior), estado de súbito desequilíbrio ou desajuste emocional, estado declínio, episódio desgastante, complicado. Seu significado econômico nos diz se tratar de grave desequilíbrio conjuntural entre a produção e o consumo, acarretando aviltamento dos preços, da moeda, onda de falências, desemprego etc., ou, ainda, uma fase de transição entre um surto de prosperidade e outro de depressão. Todos os significados têm pertinência relativa.

De imediato, deve-se perguntar se a crise atual não é só conjuntural. A mídia nos induz a crer que sua origem foi a "bolha" especulativa! Mas sua gravidade a coloca como a maior da história do capitalismo, superior à de 1929, no que concerne aos seus aspectos destrutivos. Então, faz sentido se argumentar sobre suas causas como tendo sido as hipotecas subprimes? Ou se trata de um processo bem mais profundo, que coloca em causa os fundamentos do capitalismo? Seria uma crise de reprodução do capital ou uma crise subconsumista? Se as contradições do modo de produção levam-no, inevitavelmente, às crises peri- 
ódicas, pode-se prever um colapso definitivo para ele? O capitalismo desaparecerá por um processo de transição a outro modo de produção e a outra formação social correspondente? Não conseguiremos responder a todas estas questões nos limites deste dossiê, mas apenas algumas delas. Éo que pretendemos.

A crise, da qual tratamos aqui exibe uma aparência episódica e conjuntural, mas, também, um conteúdo de longa gestação, de acúmulo quantitativo, que termina exibindo os limites estruturais do capitalismo. Eles podem ser condensados na fórmula de Marx e expressos na assertiva de que o maior limite é o próprio capital. Marx dizia que as crises são cíclicas e ajudam a sanear o metabolismo do sistema, do mesmo jeito que os psicólogos dizem que as crises têm, por vezes, efeito benéfico, semelhante ao médico que enxerga na doença de um corpo um momento de desequilíbrio entre os elementos de seu funcionamento, mas que podem ser revertidos. O objeto deste dossiê é entendido, também, como uma "disfunção" do organismo social mundial, que vem se manifestando periodicamente na história de sua "evolução". Mas, na abordagem da maior parte dos cientistas sociais, as crises do sistema capitalista mundial não são a expressão - como para nós, de um organismo envelhecido na atualidade do século XXI pelo funcionamento de suas contradições. Ele atingiu uma "idade" evolutiva na qual todos os remédios parecem atiçar os estertores de suas doenças múltiplas. Suas crises não são "disfunções” de administração superáveis pela boa dose de um maior liberalismo ou de um maior keynesianismo.

Nosso método, aqui, pressupõe a crise como um processo de múltiplos condicionantes e determinações. Embora ele seja totalizante, os limites do presente dossiê nos obrigam a reduzir sua explicação praticamente à Crise Econômica. É a crise - como sobressairá nos textos - uma manifestação orgânico-estrutural e sistêmica do modo de produção capitalista que alcançou um grau de distorções irreversíveis. Estas têm suas origens no núcleo estruturador do valor. A crise é o fruto podre de um longo processo dominado pelo capital fictício. Ele não mostrou todas as suas formas, nem consequências, mas concentra todos os elementos de uma crise da modernidade capitalista.

Os autores que apresentamos aqui também entendem assim e os convidamos exatamente porque adotam tal perspectiva. São pensadores experientes, que têm na crise não apenas uma palavra a ser concebida, apenas, na sua semântica. De formas diferenciadas, mas regulares, o fenômeno da crise constitui o objeto de pesquisa permanente para eles. As confluências existem, pois, embora as nuances sejam inevitáveis e, talvez até, discordâncias menores. Todos já são conhecidos no Brasil, uns mais outros menos, e não somente em suas "corporações" de ofício. Todos colaboram com "O Olho da História" (www.oolhodahistoria.org), revista que vem dedicando, sistematicamente, parte de suas atenções à crise.

Denis Collin abre o dossiê com o texto $A$ crise da humanidade. Para ele a crise atual é total. Afeta todos os aspectos da vida humana numa escala mundial. O sistema de acumulação ilimitada de valor e lucratividade sempre ascendente não pode mais ser perpetuado sem ameaçar a própria civilização.

O artigo de Robert Rollinat busca desvendar as causas da crise e as formas que tomou, nos últimos cinco anos, a exacerbação da concorrência e a "guerra cambial". Relata os "eventos crônicos", realiza uma avaliação da "dívida sobreana" e do futuro do euro. Ocorre que a imposição de novos termos para a valorização do capital e complexo mecanismo de "destruição-criação" de valor se confunde com a superprodução de capital e de mercadorias. A extorsão de mais-valia permanece condição "sine qua non" do lucro e o caráter brutal que o capital financeiro adquiriu hoje - não só em relação ao trabalho, mas em relação a todas as categorias da vida social, é inevitável. Mas ele bebeu do próprio veneno!

Para Claudio Katz a crise global aprofunda as contradições das economias latino-americanas. Mecanismos instituídos como o UNASUR tornamse centrais como promotores da estabilização, mas são incapazes de fazer frente à internacionalização das finanças e ao bloqueio dos bancos nacionais 
que terminam subjugados pelos bancos estrangeiros. A volta à agro exportação e ao extrativismo reforça a dominação das empresas transacionais. O desenvolvimento manufatureiro semelhante ao modelo asiático deixa de ter espaço. Katz observa que, do ponto de vista ideológico, o neoliberalismo terminou ressuscitando o discurso neodesenvolvimentista e industrialista contrariados nacionalmente pela acumulação dos exportadores.

O texto de Rosa Maria Marques e de Paulo Nakatani analisa o impacto sobre a economia brasileira do movimento de entrada de capitais ocorrido nos últimos anos, à luz do crescimento descomunal do capital fictício e do desenvolvimento da crise econômica mundial. Destaca a magnitude de recursos envolvidos e seu impacto sobre o nível das reservas e a taxa de câmbio. Acentua um grau elevado de exposição da economia aos movimentos bruscos do capital internacional, principalmente na hipótese de um recrudescimento da crise. $\mathrm{O}$ artigo ainda traz elementos sobre a origem e o destino dos investimentos diretos realizados no país com capital estrangeiro, bem como sua importância nos processos de privatização, fusão e aquisição.

Para Michael Löwy, a crise ecológica e a econômica são expressão da crise de civilização do capitalista moderno. Este provoca a exclusão social, a pobreza, a guerra e a degradação ambiental. Os programas neoliberais, aplicados pelos governos de direita e de centro-esquerda, aprofundam os processos recessivos e a depressão, promovendo o aumento das dívidas internas e externas dos estados. Sustenta que o capitalismo não irá morrer de morte natural. Se os explorados e oprimidos não encontrarem o caminho para a transformação anticapitalista, o sistema poderá encontrar "saída" seja através de regimes totalitários ou de novas guerras. O ecossocialismo defende o desenvolvimento da propriedade coletiva dos meios de produção, rompendo com o valor de troca. Inverter a perspectiva através da realização de valores de uso, e isto subverte a própria ideia de socialismo que deve praticar a substituição das energias fósseis pelas renováveis, assim como a mudança do padrão de consumo, construindo uma nova idade civilizatória pós-capitalista.

O artigo de Paulo Balanco e Jorge Nóvoa explora as várias dimensões da crise em sua perspectiva econômica. Argumenta que as modificações criadas pelo sistema capitalista internacional, a partir dos anos 1970, traduzem as grandes limitações estruturais às quais chegou carregada de contradições. Trouxeram inovações significativas nas dimensões produtiva, financeira e geográfica em geral, mas, ao mesmo tempo, acarretaram resultados empíricos que revelam a vulnerabilidade extremada à qual está sujeita, adiando continuamente a passagem do sistema para uma nova onda expansionista "harmoniosa". Assim, multiplicamse os eventos conjunturais na forma de crises parciais, de curto-prazo, tais como as denominadas "bolhas financeiras estruturais". Trata-se de uma situação limite, que tende a conduzir a situações acentuadamente regressivas, restringindo, portanto, o quadro mais claramente civilizatório alcançado pela humanidade.

(Recebido para publicação em 05 de março de 2013)

(Aceito em 15 de março de 2013)

Jorge Luiz Bezerra Nóvoa - Doutor em Sociologia. Professor da Universidade Federal da Babia - UFBA. Áreas de investigação: Epistemologia da razão poética e a reconstrução dos paradigmas das ciências sociais; Sobre as relações entre o cinema e a história e as representações das sociedades no cinema; Marx e a teoria do conhecimento nas ciências sociais, na história e na psicanálise; História das ciências sociais e da psicanálise, História moderna e contemporânea; História do capitalismo e dos movimentos sociais; Sociologia do conhecimento e das formas de consciência social. Publicações recentes: O problema do belo em "Morte em Veneza" e "Blow-up": tensões, conflitos e contradições no real que a estética reconstrói. In: Alcides Freire Ramos, Cléria Botelho da Costa, Rosangela Patriota. (Org.). Temas de história cultural. 1ed.São Paulo: Hucitec, 2012, v. 1, p. 184-197; "Barravento": dicotomias da cultura popular religiosa afrodescendente no cinema de Glauber Rocha. Revista Porto, v. 1, p. 70-79, 2011. 
